\title{
Hubungan Asma dengan Gangguan Perilaku pada Anak
}

\author{
Diana Mariana Damanik, Retno Sutomo, Amalia Setyati \\ Bagian Ilmu Kesehatan Anak Fakultas Kedokteran Universitas Gadjah Mada/RSUP Dr Sardjito, \\ Yogyakarta
}

\begin{abstract}
Latar belakang. Asma adalah salah satu penyakit pernapasan kronis dengan prevalensi yang meningkat pada anak maupun dewasa sejak dua dekade terakhir. Terdapat beberapa penelitian yang menyatakan hubungan antara asma dengan gangguan perilaku.

Tujuan. Menganalis hubungan antara asma dengan gangguan perilaku serta mengidentifikasi faktor yang terkait.

Metode. Penelitian cross sectional dilakukan pada bulan Februari sampai Juni 2012. Penelitian melibatkan 77 anak usia 4-18 tahun, yang didiagnosis asma di RSUP Sardjito dan 77 anak non asma. Subjek penelitian diambil secara consecutive serta matching usia dan jenis kelamin. Anak dengan penyakit kronis lain, cacat fisik atau mental yang berat dieksklusi dari penelitian. Gangguan perilaku pada semua subjek dinilai dengan strength and difficulties questionnaire (SDQ). Faktor yang berhubungan dengan gangguan perilaku, yaitu onset asma, derajat asma, dan penggunaan kortikosteroid inhalasi turut dianalisis dengan metode chi square serta regresi logistik.

Hasil. Masalah perilaku ditemukan 27,3\% pada kelompok asma dan hanya 9,1\% pada kelompok non asma (OR 3,75, IK95\% 1,48-9,45, p=0,003). Gangguan emosional dan conduct problem secara signifikan lebih sering terjadi pada kelompok asma, sedangkan perilaku prososial lebih tinggi pada anak non asma. Berdasarkan analisis multivariat dengan regresi logistik ditunjukkan derajat asma merupakan faktor yang berhubungan dengan gangguan perilaku (OR 8,83, IK95\% 2,02-38,60, p=0,01) dan conduct problem (OR 6,35 IK95\% 1,48-27,25, p=0,01).

Kesimpulan. Gangguan perilaku lebih sering terjadi pada anak dengan asma dibandingkan anak sehat serta berhubungan dengan derajat asma. Sari Pediatri 2015;16(6):391-6.
\end{abstract}

Kata kunci: asma, gangguan perilaku, anak

\footnotetext{
Alamat korespondensi:

Dr. Diana Mariana Damanik. Bagian Ilmu Kesehatan Anak FK UGM/ SMF Kesehatan Anak/RSUP DR. Sardjito, Jl. Kesehatan No. 1, Yogyakarta 55284, Telp (0274) 561616, 587333 Psw. 543. E-mail: diana_md09@yahoo.com
}

sma merupakan gangguan inflamasi kronis
yang menyebabkan hiperresponsivitas jalan
napas sehingga menimbulkan episode
wheezing (mengi) berulang, sesak napas, 
Episode tersebut berkaitan dengan bronkokonstriksi dengan derajat yang bervariasi dan biasanya reversibel secara spontan maupun dengan pengobatan. ${ }^{1}$

Terjadi peningkatan prevalensi asma, baik pada anak maupun dewasa, sejak dua dekade terakhir. Asma tidak hanya terkait dengan permasalahan medis, tetapi juga masalah psikososial, salah satunya adalah masalah perilaku. Sebuah metaanalisis menyatakan bahwa anak asma akan mengalami gangguan perilaku lebih sering dibandingkan anak normal. ${ }^{2}$ Prevalensi gangguan perilaku berkisar antara 10\%-20\%. ${ }^{3,4}$ Sampai saat ini, belum ada penelitian yang lebih lanjut tentang hal tersebut di Indonesia. Sampai saat ini, penyebab gangguan perilaku belum diketahui dengan pasti. Penelitian sebelumnya menyatakan derajat asma berat, onset asma di bawah 3 tahun, dan penggunaan obat kortikosteroid berperan dalam terjadinya gangguan perilaku. ${ }^{5-8}$ Penelitian bertujuan untuk menganalisis hubungan antara asma dengan gangguan perilaku.

\section{Metode}

Penelitian dengan rancangan cross sectional ini dilakukan pada bulan Maret 2011 sampai dengan Februari 2012. Pengambilan sampel dilakukan dengan cara consecutive sampling. Kelompok sampel adalah anak usia 4-18 tahun yang telah terdiagnosis asma dan sebagai pembanding adalah anak tanpa asma dalam jumlah yang sama. Subjek dieksklusi jika memiliki penyakit kronis selain asma serta kelainan mental psikologis, seperti sindrom Down atau autis dan tidak tinggal bersama orang tua. Penelitian ini menggunakan matching, yaitu pada variabel umur dan jenis kelamin.

Gangguan perilaku dinilai dengan strength and difficulties questionnaire (SDQ). Terdapat 4 kategori gangguan perilaku yang dinilai, yaitu hiperaktivitas, emosi, conduct problems, dan gangguan hubungan sesama. Perilaku prososial juga turut dianalisis. Pada kelompok asma dinilai hubungan gangguan perilaku dengan onset asma $<3$ tahun, derajat asma berat, dan penggunaan kortikosteroid inhalasi.

Analisis bivariat dilakukan dengan uji $\mathrm{x}^{2}$ - chisquare untuk menilai hubungan antara asma dengan gangguan perilaku. Analisis multivariat dengan regresi logistik untuk menilai kekuatan hubungan antara berbagai variabel yang mempunyai $p<0,25$ pada analisis bivariat, terhadap kejadian gangguan perilaku pada anak dengan asma. Tingkat kemaknaan yang dipakai yaitu $\mathrm{p}<0,05$ dan pengolahan data dengan menggunakan program SPSS. Penelitian ini telah mendapatkan persetujuan dari Komite Etik Penelitian Kesehatan (KEPK) Fakultas Kedokteran UGM.

\section{Hasil}

Anak asma dan non asma yang memenuhi kriteria inklusi dan eksklusi, sejumlah masing-masing 77 orang, diikutkan sebagai subjek penelitian. Karakteristik usia dan jenis kelamin tidak jauh berbeda antara kedua

Tabel 1. Karakteristik subjek penelitian

\begin{tabular}{lccc}
\hline Parameter & Asma $(\mathrm{n}=77)$ & Non asma $(\mathrm{n}=77)$ & $\mathrm{p}$ \\
\hline Usia & & & \\
$\quad$ Rerata (SD) & $8,37(3,5)$ & $9,3(4,0)$ & 0,057 \\
$\begin{array}{l}\text { Jenis kelamin, (n, \%) } \\
\quad \text { Perempuan }\end{array}$ & $36(48,6)$ & $38(51,4)$ & 0,747 \\
$\quad$ Laki-laki & $41(51,3)$ & $39(48,8)$ & \\
Pendidikan ibu, (n, \%) & $6(13,3)$ & $39(86,7)$ & 0,001 \\
$\quad$ Rendah & $71(65,1)$ & $38(34,9)$ & \\
$\quad$ Tinggi & $3(9,4)$ & $29(90,6)$ & 0,001 \\
Pendidikan ayah, (n, \%) & $74(60,7)$ & $48(39,3)$ & \\
$\quad$ Rendah & & \\
$\quad$ Tinggi & $10(33,3)$ & $20(66,7)$ & 0,038 \\
Tingkat sosio ekonomi, (n, \%) & $67(54,5)$ & $56(45,5)$ & \\
$\quad$ Miskin & & & \\
$\quad$ Tidak miskin & & & \\
\hline
\end{tabular}

Keterangan: ${ }^{*} \mathrm{p}<0,05$ bermakna secara statistik 
Diana Mariana Damanik dkk: Hubungan asma dengan gangguan perilaku pada anak

Tabel 2. Analisis bivariat tingkat sosioekonomi dan pendidikan orang tua terhadap gangguan perilaku

\begin{tabular}{lccccc}
\hline & \multicolumn{2}{c}{ Gangguan perilaku } & & \\
\cline { 2 - 3 } Variabel & $\begin{array}{c}\text { Ya } \\
\mathrm{n}(\%)\end{array}$ & $\begin{array}{c}\text { Tidak } \\
\mathrm{n}(\%)\end{array}$ & OR & IK95\% & $\mathrm{p}$ \\
\hline $\begin{array}{l}\text { Pendidikan ayah } \\
\quad \text { Rendah }\end{array}$ & $5(15,5)$ & $27(84,4)$ & 0,18 & $0,80-0,44$ & 0,67 \\
$\quad$ Tinggi & $23(18,9)$ & $99(81,1)$ & & & \\
Pendidikan ibu & $7(15,6)$ & $38(84,4)$ & 0,30 & $0,65-0,38$ & 0,58 \\
$\quad$ Rendah & $21(19,3)$ & $88(80,7)$ & & & \\
$\quad \begin{array}{l}\text { Tinggi } \\
\text { Sosioekonomi }\end{array}$ & & & & \\
$\quad$ Miskin & $7(23,2)$ & $23(76,7)$ & 0,6 & $0,43-0,28$ & 0,427 \\
$\quad$ Tidak miskin & $21(17,1)$ & $103(82,9)$ & & & \\
\hline
\end{tabular}

Keterangan: ${ }^{*} \mathrm{p}<0,05$ bermakna secara statistik

Tabel 3. Analisis bivariat klasifikasi skor SDQ antara kelompok asma dan non asma $(\mathrm{n}=77)$

\begin{tabular}{|c|c|c|c|c|c|}
\hline Variabel & Asma (\%) & Non asma (\%) & $\mathrm{p}$ & OR & IK95\% \\
\hline \multicolumn{6}{|c|}{ Gangguan perilaku } \\
\hline $\mathrm{Ya}$ & $21(75)$ & $7(25)$ & 0,003 & 3,75 & $1,48-9,45$ \\
\hline Tidak & $56(44,4)$ & $70(55,6)$ & & & \\
\hline \multicolumn{6}{|c|}{ Hiperaktif } \\
\hline $\mathrm{Ya}$ & $8(72,7)$ & $3(27,2)$ & 0,11 & 2,86 & $0,72-11,29$ \\
\hline Tidak & $69(48,2)$ & $74(51,7)$ & & & \\
\hline \multicolumn{6}{|c|}{ Conduct problems } \\
\hline $\mathrm{Ya}$ & $25(73,5)$ & $9(26,5)$ & 0,002 & 3,63 & $1,56-8,44$ \\
\hline Tidak & $52(43,3)$ & $68(56,7)$ & & & \\
\hline \multicolumn{6}{|c|}{ Gangguan emosi } \\
\hline Ya & $29(69)$ & $13(31)$ & 0,04 & 2,97 & $1,40-6,30$ \\
\hline Tidak & $48(42,8)$ & $64(57,2)$ & & & \\
\hline \multicolumn{6}{|c|}{ Peer problem } \\
\hline $\mathrm{Ya}$ & $12(63,1)$ & $7(36,8)$ & 0,22 & 1,84 & $0,68-4,87$ \\
\hline Tidak & $65(48,1)$ & $70(51,9)$ & & & \\
\hline \multicolumn{6}{|c|}{ Perilaku prososial } \\
\hline $\mathrm{Ya}$ & $72(93,5)$ & $77(100)$ & 0,02 & 2,06 & $1,75-2,44$ \\
\hline Tidak & $5(6,5)$ & $0(0)$ & & & \\
\hline
\end{tabular}

Keterangan: ${ }^{*} \mathrm{p}<0,05$ bermakna secara statistik

kelompok (Tabel 1). Pada karakteristik tingkat sosio ekonomi dan pendidikan orang tua, terdapat perbedaan antara kelompok anak asma dibandingkan dengan anak non asma. Namun, analisis bivariat menunjukkan bahwa tidak terdapat hubungan yang bermakna secara statistik $(p>0,05)$ antara ketiga karakteristik tersebut dengan gangguan perilaku (Tabel 2). Distribusi jenis kelamin relatif sama antara anak laki-laki dan perempuan ( $48,6 \%$ vs $51,3 \%)$. Distribusi usia antara 3-17 tahun dengan rerata usia 8,37 $\pm 3,5$ tahun.

Gangguan perilaku dilihat berdasarkan skor kesulitan total. Prevalensi gangguan perilaku lebih besar pada pasien
Tabel 4. Analisis multivariat dengan regresi logistik faktor yang berpengaruh terhadap kejadian gangguan perilaku dan conduct problems

\begin{tabular}{lccc}
\hline Variabel & OR & IK95\% & $\mathrm{p}^{*}$ \\
\hline Gangguan perilaku & & & \\
$\quad$ Umur onset asma & 3,50 & $0,98-12,78$ & 0,052 \\
$\quad$ Derajat asma & 30,88 & $3,00-316,34$ & 0,004 \\
$\quad$ Kortikosteroid inhalasi & 0,12 & $0,01-1,08$ & 0,059 \\
Conduct problems & & & \\
$\quad$ Umur onset asma & 2,04 & $0,71-5,89$ & 0,18 \\
$\quad$ Derajat asma & 6,35 & $1,48-27,25$ & 0,01 \\
\hline
\end{tabular}

Keterangan: ${ }^{*} \mathrm{p}<0,05$ bermakna secara statistik 
asma dibandingkan non asma $(27,3 \%$ vs $9,1 \%)$ yang bermakna secara statistik (nilai $\mathrm{p}=0,003$ ). Pada kelompok asma, $75 \%$ anak mengalami gangguan perilaku, conduct problems $73,5 \%$, dan gangguan emosi $69 \%$ lebih tinggi dan bermakna secara statistik dibandingkan kelompok non asma. Penelitian juga menunjukkan persentase perilaku prososial lebih tinggi pada kelompok non asma dibandingkan kelompok asma.

Onset dan derajat asma merupakan faktor yang secara statistik terbukti berpengaruh pada gangguan perilaku. Anak dengan derajat asma berat berisiko 8,83 kali memiliki gangguan perilaku dibanding derajat

Tabel 5. Faktor yang berpengaruh terhadap gangguan perilaku, conduct problems, gangguan emosi, dan perilaku prososial

\begin{tabular}{|c|c|c|c|c|c|}
\hline Variabel & $\begin{array}{c}\mathrm{Ya} \\
\mathrm{n}(\%)\end{array}$ & $\begin{array}{l}\text { Tidak } \\
\text { n (\%) }\end{array}$ & OR & IK95\% & $\mathrm{p}^{*}$ \\
\hline \multicolumn{6}{|c|}{ - Gangguan perilaku } \\
\hline \multicolumn{6}{|c|}{ Umur onset asma (tahun) } \\
\hline$<3$ & $16(36,3)$ & $28(63,6)$ & 3,2 & $1,03-9,93$ & 0,03 \\
\hline$\geq 3$ & $5(15,1)$ & $28(84,8)$ & & & \\
\hline \multicolumn{6}{|l|}{ Derajat asma } \\
\hline Berat & $7(70)$ & $3(30)$ & 8,83 & $2,02-38,60$ & 0,01 \\
\hline Tidak berat & $14(20,8)$ & $53(79,2)$ & & & \\
\hline \multicolumn{6}{|c|}{ Penggunaan kortikosteroid inhalasi } \\
\hline Ya & $3(15,7)$ & $16(84,3)$ & 0,41 & $0,10-1,62$ & 0,19 \\
\hline Tidak & $18(31)$ & $40(69)$ & & & \\
\hline \multicolumn{6}{|c|}{ - $\quad$ Conduct problems } \\
\hline \multicolumn{6}{|c|}{ Umur onset asma (tahun) } \\
\hline$<3$ & $17(38,6)$ & $27(61,4)$ & 1,96 & $0,72-5,35$ & 0,18 \\
\hline$\geq 3$ & $8(12,9)$ & $54(87,1)$ & & & \\
\hline \multicolumn{6}{|l|}{ Derajat asma } \\
\hline Berat & $7(70)$ & $3(30)$ & 6,35 & $1,48-27,25$ & 0,01 \\
\hline Tidak berat & $14(20,8)$ & $53(79,2)$ & & & \\
\hline \multicolumn{6}{|c|}{ Penggunaan kortikosteroid inhalasi } \\
\hline Ya & $6(31,5)$ & $13(68,5)$ & 0,94 & $0,31-2,88$ & 0,92 \\
\hline Tidak & $19(32,7)$ & $39(67,3)$ & & & \\
\hline \multicolumn{6}{|c|}{ - Gangguan emosi } \\
\hline \multicolumn{6}{|c|}{ Umur onset asma (tahun) } \\
\hline$<3$ & $17(38,6)$ & $27(61,2)$ & 1,10 & $0,43-2,88$ & 0,83 \\
\hline$\geq 3$ & $12(36,3)$ & $21(63,7)$ & & & \\
\hline \multicolumn{6}{|l|}{ Derajat asma } \\
\hline Berat & $6(60)$ & $4(40)$ & 2,87 & $0,73-11,20$ & 0,11 \\
\hline Tidak berat & $23(34,3)$ & $44(65,7)$ & & & \\
\hline \multicolumn{6}{|c|}{ Penggunaan kortikosteroid inhalasi } \\
\hline $\mathrm{Ya}$ & $5(26,3)$ & $14(73,7)$ & 0,50 & $0,16-1,59$ & 0,24 \\
\hline Tidak & $24(41,4)$ & $34(58,6)$ & & & \\
\hline - Perilaku pr & & & & & \\
\hline \multicolumn{6}{|c|}{ Umur onset asma (tahun) } \\
\hline$<3$ & $2(4,5)$ & $42(95,5)$ & 0,47 & $0,07-3,27$ & 0,42 \\
\hline$\geq 3$ & $3(9)$ & $30(91)$ & & & \\
\hline \multicolumn{6}{|l|}{ Derajat asma } \\
\hline Berat & $2(20)$ & $8(89)$ & 5,33 & $0,77-36,90$ & 0,06 \\
\hline Tidak berat & $3(4,4)$ & $64(95,6)$ & & & \\
\hline \multicolumn{6}{|c|}{ Penggunaan kortikosteroid inhalasi } \\
\hline $\mathrm{Ya}$ & $2(10,5)$ & $17(89,5)$ & 2,15 & $0,33-13,99$ & 0,41 \\
\hline Tidak & $3(5,1)$ & $55(94,9)$ & & & \\
\hline
\end{tabular}

Keterangan: ${ }^{*} \mathrm{p}<0,05$ bermakna secara statistik 
tidak berat. Selain itu, anak dengan onset asma $<3$ tahun berisiko 3,2 kali mengalami gangguan perilaku dibandingkan onset asma $>3$ tahun. Penggunaan kortikosteroid inhalasi tidak berhubungan dengan gangguan perilaku pada anak asma (Tabel 4).

Derajat asma berat secara signifikan berpengaruh pada conduct problems. Anak pada kelompok asma derajat berat, $70 \%$ mengalami gangguan conduct problems dan berisiko 6,35 kali lebih besar memiliki conduct problems dibandingkan asma tidak berat. Hasil analisis bivariat faktor yang berpengaruh pada gangguan emosi dan perilaku prososial pada anak dengan asma. Berdasarkan analisis tidak ditemukan faktor yang signifikan berpengaruh pada gangguan emosi dan prososial (Tabel 5).

\section{Pembahasan}

Prevalensi gangguan perilaku lebih tinggi pada anak asma dibandingkan anak tanpa asma (27,3\%). Penelitian sebelumnya menyatakan prevalensi gangguan perilaku anak dengan asma berkisar antara 10\%-20\%, tidak jauh berbeda dengan penelitian ini. ${ }^{3,4}$ Risiko terjadinya gangguan perilaku anak dengan asma 3,75 kali lebih besar dibandingkan anak tanpa asma.

Gangguan emosi dan conduct problem lebih tinggi pada kelompok asma. Sementara itu, perilaku prososial rendah lebih tinggi pada kelompok non asma. Penelitian Calam dkk, ${ }^{5}$ menggunakan instrumen yang sama, mendapatkan OR yang lebih besar dan terdapat hubungan statistik yang bermakna untuk semua kategori. Penelitian Maesano dkk, ${ }^{9}$ menggunakan instrumen yang sama, menyatakan bahwa terdapat hubungan antara asma dengan gangguan emosional dan conduct problem, sedangkan skor SDQ yang lain tidak dijelaskan pada penelitian tersebut.

Kami melakukan analisis terhadap faktor yang memengaruhi hasil skor SDQ pada anak asma. Asma derajat berat merupakan faktor yang berhubungan dengan gangguan perilaku dan conduct problems. Penelitian Calam $\mathrm{dkk}^{5}$ mendapatkan asma dengan derajat berat merupakan faktor yang berpengaruh terhadap semua kategorik skor SDQ jika dibanding dengan anak sehat. Penelitian Maesano $\mathrm{dkk}^{9}$ mendapatkan hubungan antara asma persisten dengan gangguan emosi dan conduct problem. Penelitian Halterman $\mathrm{dkk}^{4}{ }^{4}$ dengan menggunakan instrumen berbeda, juga mendapatkan asma persisten berpenga- ruh terhadap masalah perilaku, berupa gangguan berteman, kecemasan, dan pemalu.

Pada penelitian ini menunjukkan bahwa onset asma kurang dari 3 tahun juga memengaruhi gangguan perilaku. Anak dengan onset asma kurang dari 3 tahun akan 3,2 kali lebih mudah mengalami gangguan perilaku dibandingkan asma dengan onset di atas 3 tahun. Penelitian juga menunjukkan bahwa persentase conduct problem, gangguan emosi dan perilaku prososial rendah lebih tinggi pada anak asma dengan onset di bawah 3 tahun dibandingkan di atas 3 tahun. Penelitian Maesano dkk, ${ }^{9}$ menggunakan instrumen yang sama, mendapatkan hubungan antara onset asma awal (kurang dari usia 4 tahun) dengan timbulnya gangguan emosi dan conduct problem. Menurut Mrazek dkk, ${ }^{8}$ persentase gangguan tidur, pemurung dan penakut pada anak asma dengan onset di bawah 3 tahun lebih tinggi dibandingkan anak sehat. Pada penelitian sebelumnya, saat anak berusia 4 dan 6 tahun, onset asma $<3$ tahun berhubungan dengan timbulnya gangguan perilaku. Kegagalan adaptasi anak terhadap penyakit yang dialaminya disebabkan kemampuan anak usia 3 tahun dalam merespon stressor akut masih sangat terbatas.

Penggunaan kortikosteroid inhalasi tidak terbukti berpengaruh pada gangguan perilaku. Hal tersebut kemungkinan disebabkan sampel penelitian ini yang menggunakan steroid inhalasi hanya $24,6 \%$-dengan rincian dosis tinggi $1,2 \%$, medium $7,7 \%$ dan rendah $15,5 \%$. Tidak ada sampel yang menggunakan kortikosteroid inhalasi lebih dari 1 jenis, kortikosteroid oral dan teofilin. Penelitian Ricardson $\mathrm{dkk}^{3}$ menyatakan bahwa penggunaan $\geq 2$ steroid inhalasi berpengaruh sebagai effect modifier pada asma berat atau persisten terhadap terjadinya gangguan cemas dan depresi. Pada laporan kasus Hederos terhadap 60 anak asma usia prasekolah yang menggunakan budesonide inhalasi dosis $4 \times 200 \mu \mathrm{g} / \mathrm{hari}$, terdapat $15 \%$ anak yang mengalami efek samping neuropsikologis, berupa agresif, hiperaktif, gangguan mood, dan enuresis. ${ }^{6}$ Penelitian Kayani dkk, ${ }^{10}$ pada anak asma eksaserbasi akut, menyatakan bahwa pemberian prednison oral dosis $2 \mathrm{mg} / \mathrm{kg} /$ hari selama 5 hari berhubungan dengan timbulnya kecemasan dan agresif jika dibandingkan dengan prednison oral dosis rendah. Namun, hal tersebut perlu diteliti lebih lanjut apakah steroid inhalasi yang menjadi penyebab langsung dari gangguan perilaku atau hanya sebagai effect modifier terutama pada anak asma berat. 
Salah satu kelemahan penelitian ini adalah jumlah sampel yang sedikit dan tidak menggunakan multi informan dalam pengisian kuesioner SDQ kuesioner dapat diisi selain oleh orangtua juga bisa dilakukan oleh guru. Pengisian oleh multi informan akan meningkatkan sensitivitas SDQ dalam mendeteksi gangguan perilaku dibandingkan satu informan orang tua atau guru saja. Disamping itu, pengisian oleh orangtua atau guru memiliki prediktor yang lebih baik dibandingkan pengisian oleh anak sendiri. ${ }^{11}$ Selain itu, pengaruh lingkungan, seperti pola asuh, kondisi psikologis orang tua, adaptasi terhadap penyakit-yang pada penelitian sebelumnya terbukti berpengaruh pada gangguan perilaku anak dengan asma-tidak diteliti pada penelitian ini. ${ }^{8,12}$ Variabel tersebut dapat memengaruhi kondisi psikologis anak asma yang berperan dalam pembentukan karakter perilaku anak.

\section{Kesimpulan}

Gangguan perilaku lebih sering terjadi pada anak dengan asma dibandingkan anak tanpa asma terutama conduct problem dan gangguan emosi. Perilaku prososial lebih banyak terdapat pada anak tanpa asma. Asma berat (persisten) dan onset asma $<3$ tahun merupakan faktor yang memengaruhi terjadinya gangguan perilaku pada anak dengan asma. Penggunaan kortikosteroid inhalasi tidak berpengaruh terhadap kejadian gangguan perilaku pada anak dengan asma.

\section{Daftar pustaka}

1. Byrne P, Bateman E, Bousquet J. Defenition and overview. Dalam: Global Initiative for Ashma 2009.h.1-9. Diakses pada 23 April 2015. Didapat dari: http://www. ginasthma.org/local/uploads/files/GINA_Report_2010_1. $p d f$

2. Mcquaid E, Kopel S, and Nassau J. Behavioral adjustment in children with asthma: a meta-analysis. Journal of developmental and behavioral pediatrics 2001;22:430-9.

3. Richardson L, Lozano P, Russo J, Mcculey E, Bush T, Katon W. Asthma symptom burden: Relationship to asthma severity and anxiety and depression symptom. Pediatrics 2006;118:1042-51.

4. Halterman J, Conn K, Jones E, Fagnano M, Hightower D, Szilagly P. Behavior problems among inner city children with asthma: findings from a community-based sample. Pediatrics 2006;177:192-9.

5. Calam R, Gregg L, Goodman R. Psychological adjustment and asthma in children and adolescents: the UK national mental health survey. Psychosomatic medicine 2005;67:105-10.

6. Hederos CA. Neuropsychologic changes and inhaled corticosteroids. J Allergy Clin Immunol 2004;114:4512.

7. Stuart F, Segal T, Keady S, Adverse psychological effects of corticosteroids in children and adolescent. Archdischild J 2005;90:500-6.

8. Mrazek D, and Schman W. Early asthma onset: risk of emotional and behavior difficulties. J Child Psycho Psychiat 1998;39:247-54.

9. Maesano AI, Zhou C, Baiz N, Banerjee S, Charpin DA, Caillaud D. Externalizing and internalizing behavioral problems related to asthma in school children. Eur J Allergy Clin Immunol 2013;68:1471-4.

10. Kayani S, and Shannon D. Adverse behavioral effects of treatment for acute exacerbation asthma in children: a comparison of two dose of oral steroid. Cheast J 2002;122:624-8.

11. Goodman R and Scoot S. Comparing the Strength and Difficulties Questionnaire and the Child Behavior Checklist: Is small beautiful? J Abnormal Child Psychol 1999;27:17-24.

12. Klinnert M, Kaugars AS, Strand M, Silveira L. Family psychological factors in relation to children's asthma status and behavioral adjustment at age 4 . Family process 2008;47:411-61. 